\title{
PERANAN PARTISIPASI PENDIDIKAN DALAM MENINGKATKAN PARTISIPASI ANGKATAN KERJA DI DKI JAKARTA TAHUN 2009-2013
}

\author{
Yessy Purnamasari ${ }^{1}$ \\ Dini Amaliah ${ }^{2}$ \\ ${ }^{1}$ Mahasiswa Prodi Pendidikan Ekonomi Universitas Indraprasta PGRI \\ ${ }^{2}$ Dosen Program Studi Pendidikan Ekonomi Universitas Indraprasta PGRI \\ E-Mail: chipurnamasari@gmail.com \\ dini230612@gmail.com
}

\begin{abstract}
Abstrak
Tujuan dari penelitian adalah untuk mengetahui seberapa besar peranan partisipasi pendidikan (APS, APM dan APK) dalam meningkatkan partisipasi angkatan kerja di DKI Jakarta tahun 2009-2013. Penelitian ini dilakukan di Badan Pusat Statistik (BPS). Metode penelitian yang digunakan untuk menganalisis data adalah metode analisis regresi sederhana dan analisis regresi berganda sedangkan pengujian hipotesis menggunakan Uji-t, Uji-f dan determinasi $\left(\boldsymbol{R}^{\mathbf{2}}\right)$, yang sebelumnya telah dilakukan Uji Normalitas menggunakan Uji Normal Probability Plot, Uji Multikolonieritas dan Uji Heteroskedastisitas. Berdasarkan Uji Normalitas dikatakan bahwa residual berdistribusi normal, uji multikolenieritas VIF = $1,020<10$ dan nilai Tolerance $=0,980>0,1 ;$ sehingga disimpulkan tidak terdapatmultikolinearitas antara $\mathbf{X}_{1}, \mathbf{X}_{2}$ dan $\mathbf{X}_{3}$ dalam model regresi dan uji heteroskedastisitas model penelitian tidak terdapat permasalahan heteroskedastisitas.Berdasarkan dari Uji Hipotesis yang dilakukan dengan menggunakan pengujian parsial (Uji-t), didapatkan hasil APS dan APM berperan secara signifikan terhadap partisipasi angkatan kerja dan APK tidak berperan secara signifikan terhadap partisipasi angkatan kerja. Sedangkan pengujian simultan (uji-f) diketahui $\boldsymbol{F}_{\text {hitung }}=\mathbf{2 2 4}, \mathbf{3 3 3}>\boldsymbol{F}_{\text {tabel }}=216$ maka $\boldsymbol{H}_{\mathbf{0}}$ ditolak dan disimpulkan partisipasi pendidikan (APS, APM dan APK) berperan signifikan secara simultan terhadap partisipasi angkatan kerja. Nilai $\mathrm{R}^{2}$ 0,9985. Hal ini berarti 99,85\% dipengaruhi oleh variabel-variabel independen dan sisanya $0,15 \%$ dipengaruhi diluar model.
\end{abstract}

Kata Kunci:Partisipasi Pendidikan (APS, APM dan APK), Partisipasi Angkatan Kerja (TPAK).

\section{PENDAHULUAN}

Amanat Undang-Undang Dasar 1945 beserta amandemennya (pasal 31 ayat 2), melalui pendidikan pemerintah secara konsisten berupaya meningkatkan SDM penduduk Indonesia. Untuk menciptakan SDM yang handal dan berkualitas, siap bersaing di era globalisasi.

Tabel 1. Data Sensus Penduduk DKI Jakarta Tahun 2009-2013

\begin{tabular}{|c|c|c|c|c|c|c|}
\hline Rincian & $\begin{array}{c}\text { Satuan/ } \\
\text { Unit }\end{array}$ & 2009 & 2010 & 2011 & 2012 & 2013 \\
\hline Penduduk & Juta & 9,22 & 9,61 & 9,89 & 9,99 & 10,09 \\
\hline Laju Pertumbuhan & $\%$ & 0,92 & 1,42 & 1,08 & 1,01 & 0,99 \\
\hline TPAK & $\%$ & 66,60 & 67,83 & 69,36 & 71,56 & 68,09 \\
\hline Penduduk Miskin & Orang & 323,2 & 312,2 & 363,4 & 363,2 & 354,2 \\
\hline
\end{tabular}

Sumber: BPS DKI Jakarta, Diolah

Dari tabel di atas terlihat bahwa dari tahun 2009-2013 penduduk di DKI Jakarta mengalami peningkatan tiap tahunnya, yaitu dari tahun 2009 sebesar 9,22 juta orang dan 
pada tahun 2013 sebesar 10,09 juta orang. Laju pertumbuhan penduduk di DKI Jakarta juga mengalami peningkatan yaitu pada tahun 2009 sebesar $0,92 \%$ meningkat pada tahun 2013 menjadi 0,99\%. Tingkat Partisipasi Angkatan Kerja (TPAK) mengalami peningkatan pada tahun 2013 sebesar $68,09 \%$. Sedangkan penduduk miskin mengalami peningkatan dari tahun 2009 sebesar 323,2 ribu orang menjadi 354,2 ribu orang. Walaupun penduduk miskin tidak setinggi di tahun 2011 yaitu sebesar 363,4 ribu orang.

Menurut Badan Pusat Statistik (BPS, 2014) mengatakan bahwa "Laju pertumbuhan penduduk yang cepat akan meningkatkan jumlah pertumbuhan tenaga kerja dan angkatan kerja". Namun, pada kenyataannya penduduk miskin di DKI Jakarta masih mengalami peningkatan sehingga dapat dikatakan bahwa masih banyak penduduk di DKI Jakarta tidak bekerja.

Salah satu cara agar dapat meningkatkan keterampilan adalah melalui pendidikan. Karena pendidikan merupakan salah satu aspek pembangunan bangsa yang sangat penting dalam pengembangan SDM. Oleh karena itu, peningkatan mutu pendidikan harus terus diupayakan dimulai dengan membuka kesempatan seluas-luasnya kepada masyarakat untuk mengenyam pendidikan.

Peran pemerintah dalam meningkatkan mutu dan kualitas pendidikan yaitu dengan meningkatkan program wajib belajar menjadi 12 tahun untuk menggantikan program wajib belajar 9 tahun.

Menurut Koordinator Nasional NEW Indonesia, Abdul Waid di Gedung Mahkamah Konsitusi (MK), Jum'at (05/09/2014) mengatakan bahwa “jika negara hanya mewajibkan sekolah 9 tahun, bagaimana mungkin anak-anak mendapatkan pekerjaan, sedangkan saat ini jarang lowongan pekerjaan yang dibuka untuk orang yang hanya lulusan Sekolah Menengah Pertama (SMP)”.

Program wajib belajar 12 tahun dan berbagai program pendukung lainnya adalah upaya pemerintah mempercepat peningkatan kualitas SDM, sehingga pendidikan bertujuan untuk membuat SDM yang terkualifikasi dan memiliki kompetensi yang baik. Jika SDM sudah memiliki kualifikasi yang baik, maka pasar tenaga kerja pun akan mampu menyerap mereka dengan baik juga dapat meningkatkan keterampilannya dalam berwirausaha.

Sebagai bentuk monitoring penuntasan wajib belajar 12 tahun yang berkaitan dengan indikator tingkat keberhasilan pada bidang pendidikan di DKI Jakarta dapat dilihat dari pencapaian nilai Angka Partisipasi Sekolah (APS), Angka Partisipasi Murni (APM) dan Angka Partisipasi Kasar (APK).

APS, yang mengindikasikan seberapa besar akses dari penduduk usia sekolah dapat menikmati pendidikan formal di sekolah.

APM menggambarkan tingkat partisipasi penduduk usia sekolah di DKI Jakarta dengan formulasi perbandingan antara jumlah penduduk usia sekolah yang bersekolah dengan jumlah penduduk usia sekolah pada semua jenjang pendidikan pada waktu tertentu.

APK mengindikasi partisipasi penduduk yang sedang mengenyam pendidikan sesuai dengan jenjang pendidikannya. Angka APK ini bisa lebih besar dari 100\%, karena populasi murid yang bersekolah di suatu jenjang pendidikan, mencangkup anak di luar batas usia sekolah pada jenjang pendidikan yang bersangkutan.

Menteri Pendidikan dan Kebudayaan (Mendikbud) Anies Baswedan pada acara senimar South East Asia Bureau Chief The Economist, Indonesia Summit 2015, di Jakarta, Rabu (11/02/2015) mengatakan bahwa tenaga kerja yang dibutuhkan di Indonesia saat ini bukan hanya dalam jumlah yang besar, tetapi juga tenaga kerja yang 
berkualitas. Berkualitas itu artinya memiliki etos kerja yang kuat, karakter kerja yang baik, serta pengetahuan dan keterampilan yang baik. Dukungan pemerintah dalam upaya melahirkan SDM yang berkualitas, Mendikbud mengemukakan, akan mendukung peningkatan kuantitas pendidikan. Kuantitas tersebut akan disesuaikan dengan rencana pembangunan jangka panjang pemerintah. Pemerintah akan mencoba mendorong pendirian lembaga pendidikan atau sekolah di tempat-tempat yang memiliki peluang kerja tinggi.

Berdasarkan uraian latar belakang tersebut diatas maka peneliti tertarik untuk melakukan penelitian Peranan Partisipasi Pendidikan Dalam Meningkatkan Partisipasi Angkatan Kerja di DKI Jakarta Tahun 2009-2013.

\section{TINJAUAN PUSTAKA}

Partisipasi Angkatan Kerja

Menurut BPS Provinsi DKI Jakarta (2013), “angkatan kerja merupakan bagian dari penduduk usia produktif yang

bekerja dan mencari kerja".

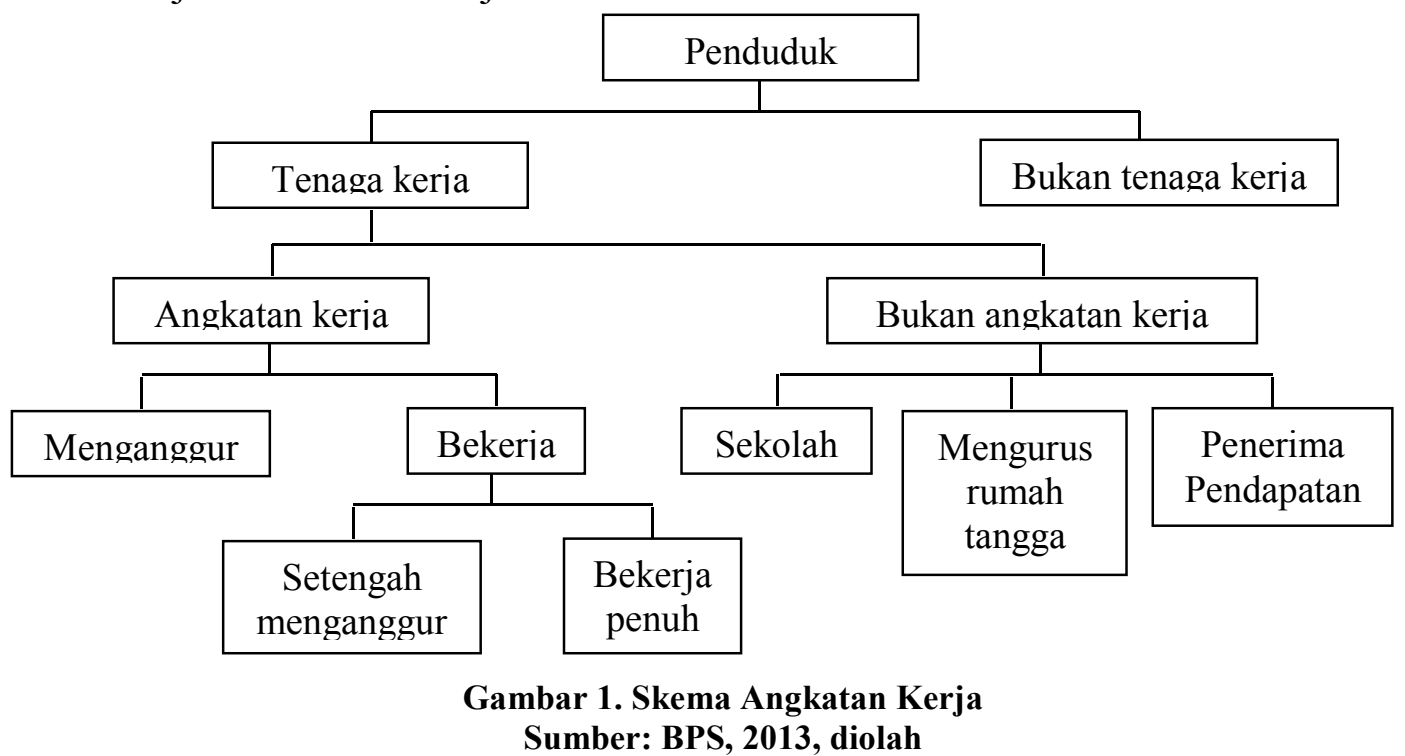

Menurut Pratama dan Mandala (2008), "angkatan kerja dibedakan menjadi tiga kelompok, yakni menganggur (Unemployed), setengah menggangur (Underemployed) dan bekerja penuh (Employed)".

1. Menganggur (Unemployed)

Yaitu mereka yang sama sekali tidak bekerja atau sedang mencari pekerjaan.

2. Setengah menggangur (Underemployed)

Yaitu mereka yang bekerja, tetapi belum dimanfaatkan secara penuh. Artinya, jam kerja mereka dalam seminggu kurang dari 35 jam.

3. Bekerja penuh (Employed)

Yaitu orang-orang yang bekerja penuh atau jam kerja mencapai 35 jam per minggu.

TPAK merupakan ukuran tingkat partisipasi penduduk dalam angkatan kerja yang dapat memberikan gambaran yang jelas sampai seberapa jauh sebenarnya penduduk yang termasuk usia kerja (15 tahun ke atas) benar-benar aktif di dalam bekerja dan tidak aktif bekerja. Jadi TPAK perbandingan antara angkatan kerja dan penduduk dalam usia kerja. Semakin besar jumlah penduduk usia kerja akan menyebabkan semakin besarnya 
angkatan kerja. Secara singkat TPAK adalah jumlah angkatan kerja di bagi dengan jumlah tenaga kerja dalam kelompok yang sama.

Simanjuntak (2001) "Faktor-faktor yang mempengaruhi tingginya TPAK meliputi: jumlah penduduk bersekolah dan mengurus rumah tangga, tingkat umur, tingkat upah, tingkat pendidikan dan kegiatan ekonomi".

\section{Indikator Tingkat Partisipasi Angkatan Kerja (TPAK)}

Indikator yang dilakukan untuk menghitung tingkat partisipasi angkatan kerja adalah rasio antara jumlah angkatan kerja dengan penduduk usia kerja, dengan rumus sebagai berikut:

$$
\boldsymbol{T P A K}=\frac{\text { Jumlah Angkatan Kerja }}{\text { Jumlah Penduduk Usia Kerja }} \times 100 \%
$$

\section{Partisipasi Pendidikan}

Pendidikan merupakan salah satu indikator utama pembangunan dan kualitas Sumber Daya Manusia (SDM), sehingga kualitas SDM sangat tergantung dari kualitas pendidikan. Menurut Hidayat (2013) "Pendidikan merupakan usaha sadar manusia dalam menciptakan diri dan masyarakat agar mempertahankan hidup dalam arus perkembangan zaman".

Angka Partisipasi Sekolah (APS) merupakan ukuran daya serap lembaga pendidikan terhadap penduduk usia sekolah. APS merupakan indikator dasar yang digunakan untuk melihat akses penduduk pada fasilitas pendidikan khususnya bagi penduduk usia sekolah. Semakin tinggi APS semakin besar jumlah penduduk yang berkesempatan mengenyam pendidikan.

Rumus:

$$
\text { APS }=\frac{\text { Jumlah penduduk umur tertentu yang masih bersekolah }}{\text { Jumlah penduduk umur tertentu }} \times 100 \%
$$

Angka Partisipasi Murni (APM) merupakan proporsi jumlah anak pada kelompok usia sekolah tertentu yang sedang bersekolah pada jenjang pendidikan yang sesuai dengan usianya terhadap jumlah seluruh anak pada kelompok usia sekolah bersangkutan. APM adalah perbandingan antara jumlah kelompok usia sekolah di jenjang pendidikan tertentu dan jumlah penduduk kelompok usia tertentu.

Rumus:

$$
\text { APM }=\frac{\text { Jumlah kelompok usia sekolah di jenjang pendidikan tertentu }}{\text { Jumlah penduduk kelompok usia tertentu }} \times 100 \%
$$

Keterangan:

Tingkat SD: Kelompok usia 7-12 tahun

Tingkat SMP: Kelompok usia 13-15 tahun.

Tingkat SMA/SMK: Kelompok usia 16-18 tahun.

APM digunakan untuk melihat penduduk usia sekolah yang dapat bersekolah tepat waktu. Bila seluruh anak usia sekolah dapat bersekolah tepat waktu, maka APM akan mencapai 100\%. Secara umum, nilai APM akan selalu lebih rendah dari nilai APK, karena APK menyangkut anak diluar usia sekolah pada jenjang pendidikan yang bersangkutan.

Angka Partisipasi Kasar (APK), mengindikasikan partisipasi penduduk yang sedang mengenyam pendidikan sesuai jenjang pendidikannya. APK merupakan proporsi jumlah penduduk yang sedang bersekolah pada suatu jenjang pendidikan tersebut. sesuai 
dengan konsep tersebut, APK merupakan persentase jumlah penduduk yang sedang sekolah.

Rumus:

$$
\text { APK }=\frac{\text { Jumlah semua siswa di tingkat pendidikan tertentu }}{\text { Jumlah penduduk usia tertentu }} \times 100 \%
$$

Nilai APK bisa lebih besar dari 100\% karena populasi murid yang bersekolah pada satu jenjang pendidikan mencakup anak di luar batas usia sekolah pada jenjang pendidikan yang bersangkutan (misal anak bersekolah di SMA/SMK berumur kurang dari 16 tahun atau lebih dari 18 tahun). Secara umum, APK digunakan untuk mengukur keberhasilan program pembangunan pendidikan yang diselenggarakan dalam rangka memperluas kesempatan bagi penduduk untuk mengenyam pendidikan. "Pendidikan sebagai penyiapan tenaga kerja diartikan sebagai kegiatan membimbing peserta didik sehingga memiliki bekal dasar untuk bekerja" (Tirtarahardja dan La Sulo, 2008).

\section{METODE PENELITIAN}

Metode penelitian yang diterapkan selama penelitian berlangsung penulis menggunakan metode asosiatif dengan mengumpulkan data yang berupa fakta yang terjadi yaitu mencatat hal-hal yang berhubungan dengan situasi dan kondisi lapangan.

Populasi dalam penelitian ini adalah data partisipasi pendidikan (APS, APM dan APK) dan partisipasi angkatan kerja (TPAK) di wilayah DKI Jakarta.

Sampel penelitian ini adalah data sekunder partisipasi pendidikan (APS, APM dan APK) dan partisipasi angkatan kerja (TPAK) di DKI Jakarta tahun 2009-2013. Data sekunder yang bersumber dari data-data statistik yang diterbitkan oleh Badan Pusat Statistik (BPS) DKI Jakarta. Sedangkan jenis data yang digunakan adalah time series dari tahun 2009-2013.

Langkah-langkah yang dilakukan dalam mencapai tujuan penelitian ini adalah: melakukan analisis regresi sederhana,analisis regresi berganda, uji asumsi klasik (uji normalitas, multikolonieritas dan heteroskedastisitas), uji hipotesis secara parsial (uji tstatistik), uji hipotesis secara simultan (uji f-statistik), uji determinasi $\mathrm{R}^{2}$.

\section{HASIL DAN PEMBAHASAN}

Hasil Uji Asumsi Klasik

1. Uji Normalitas

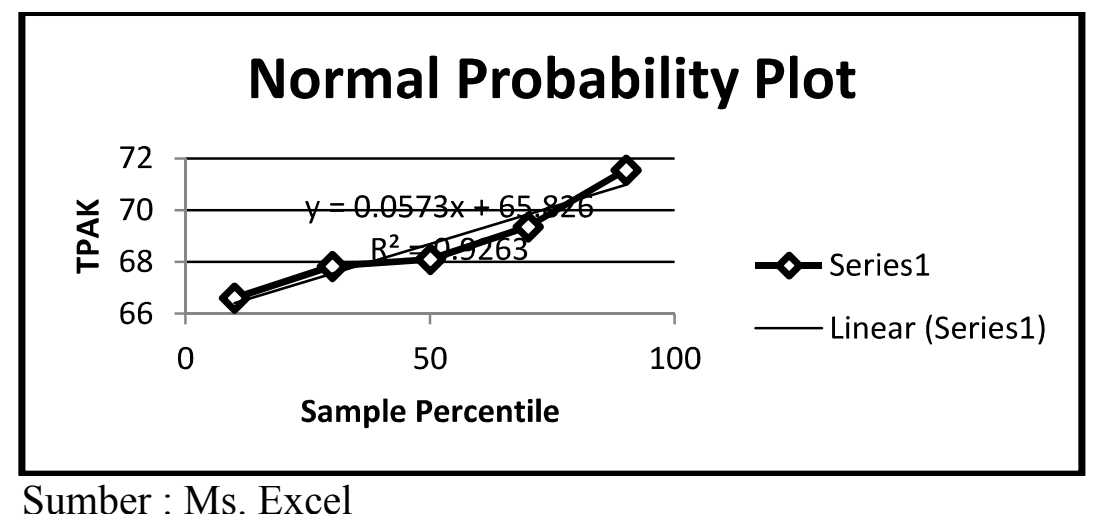

Gambar 2. Normal Probability Plot 
Berdasarkan grafik normal probability plot, dapat terlihat bahwa titik-titik menyebar disekitar garis diagonal, serta penyebarannya mengikuti arah garis diagonal, sehingga dapat disimpulkan bahwa residual berdistribusi normal.

2. Multikolinearitas

Nilai VIF $=1,020<10$ dan nilai Tolerance $=0,980>0,1 ;$ sehingga disimpulkan tidak terdapat kolinearitas/ multikolinearitas antara $\boldsymbol{X}_{\mathbf{1}}, \boldsymbol{X}_{\mathbf{2}} \boldsymbol{d a n} \boldsymbol{X}_{\mathbf{3}}$ dalam model regresi di atas.

3. Heteroskedastisitas

Tabel 2. Perhitungan heteroskedastisitas

\begin{tabular}{lrrrr} 
& Coefficients & $\begin{array}{c}\text { Standard } \\
\text { Error }\end{array}$ & t Stat & P-value \\
\hline Intercept & 0.355047489 & 3.025118421 & 0.117366476 & 0.9256224 \\
\hline X1 & -0.07516384 & 0.039175774 & -1.918630512 & 0.3058751 \\
\hline X2 & 0.04274109 & 0.024479195 & 1.746016996 & 0.3311239 \\
\hline X3 & 0.019402423 & 0.031071589 & 0.624442583 & 0.6446399 \\
\hline
\end{tabular}

Sumber: Data sekunder yang diolah

Tabel di atas menunjukan bahwa, nilai $P$-value merupakanuji regresi antara variabel independen dengan absolut residual. Sehingga diperoleh APS (X1) sebesar 0,306; APM (X2) sebesar 0,331 dan APK (X3) sebesar 0,645. Nilai variabel X1, X2 dan X3 lebih besar dari derajat kesalahan $(\alpha)=5 \%(0,05)$, maka dapat dikatakan bahwa dalam model penelitian ini tidak terdapat permasalahan heteroskedatisitas.

Analisis Regresi Linier Sederhana

1. Angka Partisipasi Sekolah (APS)

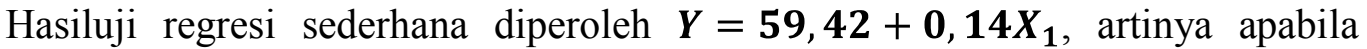
derajat kenaikan pada variabel $\mathrm{X} 1$ sebesar 1 skor maka variabel $\mathrm{Y}$ meningkat sebesar 0,14 pada konstanta 59,42.

2. Angka Partisipasi Murni (APM)

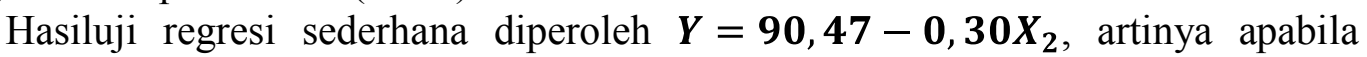
derajat kenaikan pada variabel X2 sebesar 1 skor maka variabel $\mathrm{Y}$ menurun sebesar 0,30 pada konstanta 90,47.

3. Angka Partisipasi Kasar (APK)

Hasiluji regresi sederhana diperoleh $Y=-\mathbf{6 1}, 17+\mathbf{1}, \mathbf{4 7} \boldsymbol{X}_{\mathbf{3}}$, artinya apabila derajat kenaikan pada variabel X3 sebesar 1 skor maka variabel Y meningkat sebesar 1,47 pada konstanta $-61,17$.

Analisis Regresi Linier Berganda

Hasil uji regresi berganda diperoleh $Y=-\mathbf{7 8 , 5 5}+\mathbf{2}, \mathbf{5 7 3} X_{\mathbf{1}}-\mathbf{1 , 6 4 9} X_{\mathbf{2}}+$ $\mathbf{1}, \mathbf{0 3 7} \boldsymbol{X}_{\mathbf{3}}$, artinya apabila derajat kenaikan pada variabel X1, X2 dan X3 sebesar 1 skor maka variabel Y meningkat sebesar $b 1=1,47 ; b 3=1,037$ dan menurun sebesar $b 2=1,649$ pada konstanta $-78,55$. 
Uji hipotesis secara parsial (uji t-statistik)

1. Angka Partisipasi Sekolah (APS)

Hasiluji hipotesis diperoleh $\boldsymbol{t}_{\boldsymbol{b 1}}=\mathbf{2 0 , 3 0 3}>\boldsymbol{t}_{\text {tabel }}=12,706$ maka $\boldsymbol{H}_{\mathbf{0}}$ ditolak dan disimpulkan bahwa variabel Angka Partisipasi Sekolah (APS) mempunyai peranan yang signifikan dalam meningkatkan partisipasi angkatan kerja di DKI Jakarta tahun 2009-2013 secara parsial.DKI Jakarta yang juga merupakan Ibukota negara Indonesia adalah tempat yang dituju untuk mencari pekerjaan yang layak. Seiring dengan adanya peningkatan jumlah angkatan kerja di DKI Jakarta tentunya pemerintah DKI Jakarta berupaya untuk mewujudkan penduduk DKI Jakarta yang dapat berkesempatan mengenyam pendidikan yaitu dengan cara meningkatkan fasilitas pendidikan khususnya bagi penduduk usia sekolah. Sehingga dapat meningkatkan Angka Partisipasi Sekolah (APS).

2. Angka Partisipasi Murni (APM)

Hasiluji hipotesis diperoleh $\boldsymbol{t}_{\boldsymbol{b} \mathbf{2}}=-\mathbf{2 0 , 8 2 2}<\boldsymbol{t}_{\text {tabel }}=-\mathbf{1 2}, \mathbf{7 0 6}$ maka $\boldsymbol{H}_{\mathbf{0}}$ ditolak dan disimpulkan bahwa variabel Angka Partisipasi Murni (APM) mempunyai peranan yang signifikan dalam meningkatkan partisipasi angkatan kerja di DKI Jakarta tahun 2009-2013 secara parsial.DKI Jakarta merupakan kota dengan banyaknya jumlah penduduk yang mendiami daerah tersebut. Sehingga banyak penduduk yang mengenyam pendidikan. Oleh karena itu pemerintah, mewajibkan untuk menyesuaikan proposi jumlah anak pada kelompok usia sekolah tertentu yang sedang bersekolah pada jenjang pendidikan sesuai dengan usia bersangkutan. Sehingga dapat meningkatkan Angka Partisipasi murni (APM) dan juga dapat meningkatkan jumlah partisispasi angkatan kerja di DKI Jakarta sesuai dengan usia yang produktif untuk dapat bekerja.

3. Angka Partisipasi Kasar (APK)

Hasiluji hipotesis diperoleh $\boldsymbol{t}_{\boldsymbol{b} 3}=\mathbf{1 0}, \mathbf{2 9 2}<\boldsymbol{t}_{\text {tabel }}=12,706$ maka $\boldsymbol{H}_{\mathbf{0}}$ diterima dan disimpulkan bahwa variabel Angka Partisipasi Kasar (APK) tidak mempunyai peranan yang signifikan dalam meningkatkan partisipasi angkatan kerja di DKI Jakarta tahun 2009-2013 secara parsial.Hal tersebut terjadi karena populasi murid yang bersekolah pada satu jenjang pendidikan mencangkup anak di luar batas usia sekolah pada jenjang pendidikan yang bersangkutan di DKI Jakarta misalnya anak bersekolah memiliki usia kurang dari batas usia sekolah. Sehingga APK hanya digunakan untuk mengukur keberhasilan program pembangunan pendidikan yang diselenggarakan dalam rangka memperluas kesempatan bagi penduduk untuk mengenyam pendidikan. Dan dapat dikatakan bahwa APK merupakan salah satu bukan angkatan kerja sehingga APK tidak berperan signifikan terhadap partisipasi angkatan kerja.

Uji hipotesis secara simultan (uji f-statistik)

Hasil uji hipotesis diperoleh $\boldsymbol{F}_{\text {hitung }}=\mathbf{2 2 4}, \mathbf{3 3 3}>\boldsymbol{F}_{\text {tabel }}=\mathbf{2 1 6}$ maka $\boldsymbol{H}_{\mathbf{0}}$ ditolak dan disimpulkan bahwa variabel partisipasi pendidikan (APS, APM dan APK) mempunyai peranan yang signifikan dalam meningkatkan partisipasi angkatan kerja di DKI Jakarta tahun 2009-2013 secara bersama-sama.

Uji determinasi $\mathrm{R}^{2}$

Pada uji determinasi $\mathrm{R}^{2}$ diperoleh $\mathrm{R}^{2}$ sebesar 0,9985 . Hal ini menunjukan bahwa model regresi tersebut dapat menjelaskan sebesar 99,85 persen terhadap permasalahan 
yang diteliti dalam penelitian ini. Sedangkan sisanya sebesar 0,15 persen dipengaruhi oleh variabel diluar model ini.

\section{SIMPULAN}

Berdasarkan hasil penelitian, diperoleh simpulan sebagai berikut:

1. Hasil pengujian secara parsial menunjukan bahwa:

a. Angka Partisipasi Sekolah (APS) berperan signifikan dalam meningkatkan partisipasi angkatan kerja di DKI Jakarta tahun 2009-2013.

b. Angka Partisipasi Murni (APM) berperan signifikan dalam meningkatkan partisipasi angkatan kerja di DKI Jakarta tahun 2009-2013.

c. Angka Partisipasi Kasar (APK) tidak berperan signifikan dalam meningkatkan partisipasi angkatan kerja di DKI Jakarta tahun 2009-2013.

2. Hasil pengujian secara simultan menunjukan bahwa partisipasi pendidikan (APS, APM dan APK) secara bersama-sama berperan secara signifikan dalam meningkatkan partisipasi angkatan kerja di DKI Jakarta tahun 2009-2013.

\section{SARAN}

Saran tersebut adalah sebagai berikut:

1. Partisipasi pendidikan yang dapat meningkatkan partisipasi angkatan kerja ada baiknya diimbangi dengan banyaknya lapangan pekerjaan yang tersedia untuk mengurangi tingkat pengangguran di Ibukota.

2. Penelitian ini dapat menjadi bahan kajian untuk meneliti lebih lanjut mengenai faktorfaktor lain yang dapat mempengaruhi tingkat partisispasi angkatan kerja seperti tingkat upah dan lapangan pekerjaan.

3. Pengambilan data ada baiknya lebih diperinci lagi khususnya untuk partisipasi angkatan kerja berdasarkan tingkat pendidikan agar mempermudah dalam mengelola data.

\section{UCAPAN TERIMA KASIH}

Dengan ini penulis mengucapkan rasa syukur kepada Allah SWT yang telah memberikan rahmat dan hidayah-Nya, serta penulis mengucapkanterima kasih kepada semua pihak yang telah membantu.

\section{DAFTAR PUSTAKA}

Buku:

Badan Pusat Statistik (BPS). 2013. Jakarta Dalam Angka . Jakarta: Badan Pusat Statistik Provinsi DKI Jakarta.

-----. 2014. Jakarta Dalam Angka . Jakarta: Badan Pusat Statistik Provinsi DKI Jakarta.

-----. 2013. Keadaan Angkatan Kerja Di DKI Jakarta. Jakarta: Badan Pusat Statistik Provinsi DKI Jakarta.

Hidayat, Syarif. 2013. Teori dan Prinsip Pendidikan. Tangerang: Pustaka Mandiri. 
Rahardja, Prathama, dkk. 2008. Pengantar Ilmu Ekonomi (Mikroekonomi dan Makroekonomi). Jakarta: Lembaga Penerbit Fakultas Ekonomi Universitas Indonesia.

Simanjuntak, Payaman. 2001. Pengantar Ekonomi Sumber Daya Manusia. Jakarta: LPFE-UI.

Tirtarahardja, Umar, dkk. 2008. Pengantar pendidikan, Cetakan 2. Jakarta: Rineka Cipta.

Jurnal:

Kementerian Pendidikan dan Kebudayaan. 11 Februari 2015. Seminar South East Asia Bereau Chief The Economist, Indonesia Summit 2015. www.kemendiknas.go.id/kemendikbud/berita/3813 diakses pada 25 Februari 2015.

Network For Education Watch Indonesia (NEW Indonesia). 05 September 2014. MK $\begin{array}{llll}\text { diminta } & \text { Tetapkan } & \text { Wajib } & \text { Belajar }\end{array}$ Tahun.http://www.hukumonline.com/berita/baca/lt54098ff1b5bbc/mk-dimintatetapkan-wajib-belajar-12-tahun diakses pada 15 Februari 2015.

Undang-Undang:

Peraturan Perundang-undangan

Kajian Undang-Undang Dasar Negara RI Tahun 1945 